\title{
SMALL DISTRIBUTED ENERGY RUSSIA: COMBINED HEAT AND POWER GENERATION
}

\author{
Alexander Astafev ${ }^{1,}$, Alexander Kazakov ${ }^{1}$, and Alexander Zavorin ${ }^{1}$ \\ ${ }^{1}$ National Research Tomsk Polytechnic University, 634050 Tomsk, Russia
}

\begin{abstract}
The issues and current trends of research in the field of decentralized energy supply for the period up to 2030 were considered. The analysis of the cogeneration market in Russia was done. The questions of gasification and hydrogen technologies as applied to the market of cogeneration plants were elucidated. Promising technologies for autonomous decentralized energy supply and the evaluation of their applicability to small energy were presented.
\end{abstract}

\section{Introduction}

The transition conception to innovate way of economic development, adopted in Russia, envisages a transition of country from export of raw materials to resource-innovative development with qualitative energy upgrade (both fuel and non-fuel) and related industries [1].

In energy strategy of Russia for the period to 2030 one of the tasks is modernization and creation of new energy infrastructure based on large-scale technological upgrade of energy sector in national economy. Is noted, [1] that energy safety is one of the most important components of national safety. Ensuring of energy safety is determined by the resource adequacy, economic availability, environmental and technological allowability. The resource adequacy determines the physical capabilities of sufficient energy supply for national economy and population, economic availability - the profitability of such supply at a suitable price conjuncture, environmental and technological allowability - the extraction, production and consumption possibility of energy sources under the frame of existing at each stage technologies and environmental constraints, which determines the functional safety of energy facilities [1].

The result of Russia energy strategy for the period to 2020 is existing problems, reflected in the strategy-2030:

-the weak development of the energy infrastructure in Eastern Siberia and the Far East;

-the underactive development of renewable energy and the use of local fuels in regional energy balances;

-the insufficient development of small energy and low involvement of local energy sources to energy balances of regional and local relevance.

* Corresponding author: TabakaevRB@,tpu.ru 
The priority directions of scientific and technical progress in energy sector of strategy2030:

-the creation and deployment of technological equipment complex on a modular basis for new building and existing heat supply transfer to cogeneration basis;

-the development of use renewable energy technologies and multi-functional energy complexes for autonomous energy supply in areas without centralized energy supply;

-the development effective technologies of mains energy and heat supply based on renewable energy sources;

-the expanded production and using of new fuels from different biomass types;

-the development of small energy in decentralized energy supply zone by efficiency increasing of local energy sources use, consumption reducing of imported light oil products;

-the development of heat supply in Russia and its regions based on district heating with using of modern economically and environmentally efficient cogeneration units, which have a wide power range;

-the optimal combination of centralized and decentralized heat supply with allocation of relevant zones;

-the development of systems with centrally-distributed heat generation and different resources types, located in heat consumption areas;

-the modernization and development of decentralized heat supply systems with using of high-efficiency cogeneration and other units, as well as new automated individual heat generators for combustion of various fuels;

-the equipping of consumers by stationary and mobile heat supply units as a reserve and (or) emergency heat supply.

The strategy-2030 assumes that the regional structure of generating capacities will be formed as follows:

-the development of small energy on renewable energy sources, including be replacing of local diesel generation;

-the small energy and decentralized energy supply with active use of local and waste energy sources all types will be developed, especially in areas with low density of load; also units with coal gasification and energy technological units will be developed;

-the development and implementation of regional energy programs, energy saving problems, the economic-effective maximizing of local energy and fuel sources using, the economic-effective development of decentralized and individual heat supply systems.

\section{The actual directions of researches in the decentralized energy supply field}

In the interest of Russian energy development, also distributed on the small energy facilities, necessary to developed investigations in the field of heat and power generation for autonomous decentralized consumers. As practice shows, the problem of decentralized consumers is farness from transport schemes that increases the delivery cost of fuel sources in several times [2]. Often, the reserves of local low grade fuels, which can be used as an energy carrier, has in such remote areas, but characteristics of this fuels so far as complicate the process of direct combustion in boiler furnaces, because rarely used in practice.

The memorandum about creation and activity of technological platform "Small distributed energy" states that the main applications of new technological solutions in small distributed energy [3]:

-the cogeneration units for modernization of communal infrastructure in settlements;

-the typical sets of equipment and modular technological solutions for energy supply of remoted and isolated consumers; 
-the complex local energy systems with maximum possible use of local fuel resources;

The main directions of technological development, supported under the frame of technological platform [3]:

-the technologies of heat and power generation, including fuel elements, hydrogen technology;

-the local energy sources using, including the modern technologies of peat using as a fuel resource, the gasification of local fuel resources, industrial and domestic wastes with using of synthesis gas for power generation;

Thus, the works on topics, related with investigations in the field of remote consumers energy supply, based on cogeneration units, which generates synthesis gas from local fuels with using of fuel elements, are actually.

\section{The market of cogeneration units in Russian Federation}

The development of cogeneration market in Russia is one of the strategic directions in the field of small energy. At the present time, 12 major national and 17 foreign producers of cogeneration equipment, presented at the Russian market, are existed. The most part of cogeneration stations are intended to work on natural gas and diesel fuel. Obviously, that the demand for such units is determined by relative service simplicity and its sufficient maneuverability. 6 foreign companies (GE Jenbacher, MTU, Motorgas, Tedom, Turbec, MWM) supplies equipment, worked on synthesis gas. 1 company from national (LLC ARZ "Sintur-NT") produces equipment for work on generating gas. The power range of cogeneration units is quite large: from $3.8 \mathrm{~kW}$ to $4.3 \mathrm{MW}$ of electric and from $8.9 \mathrm{~kW}$ to $5.2 \mathrm{MW}$ of heat. The main types of cogeneration units for heat and power generation are now gas reciprocating units. The efficiency of such foreign cogeneration systems generally is greater than $90 \%$, while the efficiency of national systems is about $80 \%$.

The conclusion: The modern market of Russia does not experienced deficit of cogeneration units based on combustion engines. The application area of supplied cogeneration units is limited by possibility of natural gas and diesel fuel delivery. The power of existing equipment is able to cover the needs of all consumers. The tying of power and heat generation is exists, it is not very convenient to the consumer. The foreign cogeneration stations are more efficient.

\section{The gasification role}

It is thought that the gasification of solid fuel is actual and perspective direction of research, given that this technology is allows to use low grade fuels with producing of high quality gas and solid products [4-6]. The developments, reduced heat consumption for own needs by autothermal mode of gasification, are exist. Is noted that problems of gas treatment and ensuring of work reliability for large gas generators are exist. Despite of the attractiveness of gasification as an energy technological recycling of solid fuels, is noted its low commercial attractiveness.

The conclusion: The current research level in the field of gasification is allows to create units, recycled a high quality coals and low grade fuels, but their large-scale deployment is limited by competitive advantages of existing major stations. The gasifier technologies are perhaps only option for recycling of low grade local fuels in remote decentralized areas. 


\section{The hydrogen technologies}

The relevance of hydrogen energy development is proved by following criteria:

-the ability of use in autonomous energy units;

-the demand to hydrogen in industry;

-the high competitive of hydrogen technologies;

-the environmental friendliness during hydrogen combustion.

There is an opinion that a hydrogen production by conversion of natural gas is the most expedient in terms of hydrogen production on the industrial scales [7-9]. At the same time is believed that perspective direction is hydrogen generation from biomass and solid fuel with its subsequent use in fuel elements [9]. Today there is a problem, which limited the spread of hydrogen technologies:

-the low electrical efficiency of fuel elements;

-the problem of hydrogen storage and transportation.

The low electrical efficiency of fuel elements can be offset by using of generated on them heat that allows to achieve acceptable unit efficiency in generally. The hydrogen production at place of its consumption or in one energy unit is allows to minimize problems, associated with hydrogen storage and transportation.

Is noted that the peculiarity of hydrogen units in fuel elements is its cleanliness, however, there are developments of fuel elements, worked on synthesis gas. Thus, the development of solid oxide elements, which can be worked on gas with high $\mathrm{CO} 2$ content, is actually, the working temperature range $\left(800-1000{ }^{\circ} \mathrm{C}\right)$ is allows to use such fuel elements in gas-turbine installations. For gases with high $\mathrm{CO}$ content are being developed a fuel elements with polymeric membranes (the working temperature range 120-300 ${ }^{\circ} \mathrm{C}$ ) and fuel elements with molten carbonates $\left(400^{\circ} \mathrm{C}\right)$.

The conclusion: Of course, at the present time hydrogen technologies are actually and are demanded. Is traced that diversity of approaches to technologies of hydrogen production, which primarily determined by final purpose of use. The efficient increase of source fuel using is seen in the hydrogen and energy generation in one unit with simultaneous utilization of heat, generated by fuel element. The current state of researches in the field of fuel elements shows that the requirements to cleanliness of hydrogen are decreased.

\section{The state of small and unconventional energy}

The small energy as an integral component of energetic space is recognized around the world, including Russia. Moreover, the expediency to development of artificial small distributed energy is seen positive, economic and social perspective fact. Due to geographic and economic facts in Russia the large areas are not covered by centralized energy supply and problems with provision of such areas of fuel resources are exist. Currently, the power generation in decentralized areas is mainly produced by diesel stations that not economically efficient. Wherein such areas often have reserves of local low grade fuels, but their consumption is accompanied by appropriate technical devices [11-13].

The small energy as an integral component of energetic space is recognized around the world, including Russia. Moreover, the expediency to development of artificial small distributed energy is seen positive, economic and social perspective fact. Due to geographic and economic facts in Russia the large areas are not covered by centralized energy supply and problems with provision of such areas of fuel resources are exist. Currently, the power generation in decentralized areas is mainly produced by diesel stations that not economically efficient. Wherein such areas often have reserves of local low grade fuels, but their consumption is accompanied by appropriate technical devices. 
The conclusion: Today is actually the issue of energy supply for decentralized consumers each of communal service and production. The use of cogeneration systems based on combustion engines, worked on imported diesel fuel, is a relic of the past and requires the replacement by deployment technologies of combined heat and power generation from local low grade fuel resources.

\section{The perspective technologies for autonomous decentralized energy supply}

The current researches in the field of autonomous heat and energy supply can be divided on the follows directions:

a) the co-combustion of several solid fuels (coal, biomass);

b) the production of synthesis gases;

c) the production and combustion of fuel briquettes;

d) the production of hydrogen and its use in fuel element;

e) the creation of hybrid units.

The autonomous units for power generation, combusted a coal and biomass in complex, for all that more oriented on the high quality coal, and biomass addition is allows to reduce coal consumption. This direction can't be oriented to remote areas, in which coalfields or existing transport infrastructure is absent. The all types of solid organic raw materials are suitable for synthesis gases production. The creation of such production near to existing fields of local low grade fuels is seen the perspective. Necessary to consider that the creation of power stations based on high temperature gas generators for small settlements is not expedient, because it pretty complicated technical device, specified in maintenance and required a certain qualification from personnel. The production and consumption of fuel briquettes is perspective direction in view of modern developments in the field of briquette production from low grade fuels $[14,15]$. The briquette fuel can be combust in exist furnace units with grate firing without their reconstruction.

The heat and power production from hydrogen in fuel element can be regarded as breakthrough in the energy of future. However, the certain vigilance about deployment perspectives for the field of small generation is exist, because it pretty high-tech process, required the technologies of high clean hydrogen production, now realized by conversion of natural gas.

The creation of hybrid units is one of the diversification directions in small generation. Indeed, the presence of several devices for energy generation from various sources (renewable and non-renewable) simultaneously in such units is allows to increase reliability of energy supply to consumers. But, dependence of quality energy sources (coal, gas, diesel fuel) supply is remains.

The conclusion: The choice of autonomous energy supply to decentralized consumers should be viewed based on two conditions: 1 - the presence of own quality coal and (or) natural gas resources or well-established transport schemes with acceptable delivery cost; 2 - the presence of local low grade fuel resources. The directions $a$ and $e$ are expedient at carrying out of first condition. The directions $b$ and $c$ are expedient at carrying out of second condition. The technology $\mathrm{d}$ for conversion of natural gas is not expedient because natural gas in and of itself a high quality fuel.

\section{Acknowledgments}

The reported study was partially supported by the Ministry of education and science of The Russian Federation, state order No. 13.948.2014/K. 


\section{References}

1. Energy strategy of Russia for the period to 2030 (confirm by the government edict of the Russian Federation No. 1715-pб 2009)

2. O. S. Popel, B. F. Reutov, A. P. Antropov, Therm. Eng. 57 (2010)

3. http://www.e-apbe.ru/distributed_energy/memo_TP_SDE.php

4. V. V. Lopatin, S. M. Martemyanov, Rus. Ph. J. 55 (2012)

5. I. Sircar, A. Sane, W. Wang, J.P. Gore, Fuel 119, 38 (2014)

6. S. M. Martemyanov, A. L. Maslov, Adv. Mat. Res. 1040, 620 (2014)

7. A. S. Zavorin, R. B. Tabakaev, P. Y. Novoseltsev, A. V. Astafev, MATEC Web Conf. 19 (2014)

8. A.V. Kazakov, R.B. Tabakaev, P.Y. Novoseltsev, A.V. Astafev, MATEC Web Conf. 19 (2014)

9. R.B. Tabakaev, A.V. Astafev, A.V. Kazakov, A.S. Zavorin, MATEC Web Conf., 23, (2015)

10. P.S. Gergelizhiu, S.A. Khaustov, R.B. Tabakaev, P.Y. Novoseltsev, A.V. Kazakov, A.S. Zavorin, Proc. of 2014 International Conference on Mechanical Engineering, Automation and Control Systems (TPU, Tomsk, Russia)

11. S. A. Khaustov, A. S. Zavorin, K. V. Buvakov, N. A. Zakharushkin, MATEC Web Conf. 19 (2014)

12. R. B. Tabakaev, A. V. Kazakov, A. S. Zavorin, Sol. Fuel Ch. 49 (2015)

13. R. B. Tabakaev, A. V. Astafev, A. V. Kazakov, A. S. Zavorin, MATEC Web Conf. 23 (2015)

14. R. B. Tabakaev, A. V. Astafev, A. V. Kazakov, A. S. Zavorin, M. Polsongkram, IOP Conf. Ser.: Mat. Sc. Eng. 93 (2015)

15. R. B. Tabakaev, P. S. Gergelizhiu, A. V. Kazakov, A. S. Zavorin, IOP Conf. Ser.: Mat. Sc. Eng. 66 (2014) 